\title{
2.2
}

\section{Virtue, Social Knowledge, and Implicit Bias}

\author{
Alex Madva
}

\section{Introduction}

Research suggests that most citizens of liberal democracies embrace egalitarian goals but nevertheless exhibit predictable patterns of implicit social bias in, for example, hiring and legal decisions. Recently, Gendler (2008; 2011) and Egan (2011) have argued that implicit biases put us in a kind of tragic normative dilemma, in which we cannot jointly satisfy all of our moral and epistemic requirements. Their arguments are, in part, responses to alarming evidence that the strength of implicit biases correlates with the knowledge individuals have of prevalent stereotypes, regardless whether they reflectively reject or endorse the content of those stereotypes. ${ }^{1}$ Simply knowing what the stereotypes are seems to make individuals more likely to act in biased ways.

These findings suggest an opposition between social knowledge and virtue. If mere knowledge of stereotypes hinders the possibility of acting ethically, should an individual with egalitarian goals aim to forget all she knows about discrimination and stereotypes? Returning to such a state of ignorance would incur serious costs. In such a state, she would not, for example, be in a position to recognize the injustices individuals suffer in virtue of being perceived in a stereotypical light.

\footnotetext{
1 The term "stereotype" can be problematic and misleading, because some of the cognitive processes underlying objectionable stereotypes also underlie unobjectionable and even rational forms of social cognition. Valian (1998) adopts the less charged term "schema," while Beeghly (2013) argues that we should broaden our understanding of "stereotypes" to include both rational and problematic forms of social cognition. For my purposes, the negative connotation of stereotypes is useful for keeping in view that I am talking about a class of somehow bad or undesirable states. I agree with Antony (2002) that distinguishing the "good" stereotypes from the "bad" is fundamentally an empirical question. See also Brownstein and Madva (2012a,b).
} 
If, then, she ought not surrender her social knowledge, must she simply learn to live with the unfortunate effects that knowledge has?

I argue that this apparent opposition is misguided. Social knowledge as such poses no obstacle to virtue, but rather the relative accessibility of such knowledge does. In psychology, accessibility refers to "the ease with which a particular unit of information is activated or can be retrieved from memory" (Morewedge and Kahneman, 2010: 435). In some sense, certain bits of knowledge "come to mind" more readily than others. I intend to argue that the seeming tension between virtue and knowledge of stereotypes arises primarily insofar as that knowledge becomes too readily accessible. It is possible for social agents to acquire knowledge about the existence and effects of stereotypes, while working effectively toward being more virtuous, so long as that knowledge remains relatively inaccessible.

This paper focuses on the problematic effects of social knowledge on the mental life and behavior of individuals, and, in turn, on what individuals can do about it. To consider what individuals can do is not to assume that the wrongs associated with implicit bias are primarily "individual" rather than "social." The harms and inequities suffered by individuals on the basis of race and gender depend to a great extent on social-institutional forces, and institutional change is necessary for redressing those harms. But institutions are composed both of a set of rules and laws as well as a set of individuals, and, if we want to bring about lasting change, we have to understand the roles that each plays in contributing to these large-scale harms. I focus on the role of individuals here. I intend to address what sorts of institutional policies might be warranted in light of these phenomena in future work. ${ }^{2}$

In what follows I recount the moral-epistemic dilemma posed by Gendler and Egan (Section 2). They argue that working toward the ethical ideal of being unprejudiced will inevitably incur certain "epistemic costs." I then critically examine the notion of an epistemic cost (Section 3), and describe how an agent could, in principle, pursue her ethical aims without incurring any (Section 4). Working toward this ideal ethical and epistemic state is no mere pipe dream, but depends on an agent's ability to regulate the accessibility of her social knowledge. I explain how the regulation of accessibility is key for resolving the dilemma (Section 5). I then describe a range of concrete strategies that individuals can implement to better approximate the moral-epistemic ideal (Section 6). Finally,

\footnotetext{
2 See e.g. Valian $(1998,2010)$ for many of the best institutional interventions for addressing gender bias in professional contexts; Kalev et al. (2006) for an informative meta-analysis of existing strategies to promote diversity; Levinson and Smith (2012) for a collection of essays on implicit racial bias and legal theory; and Anderson $(2010,2012 \mathrm{a})$ for pioneering work on prejudice and political philosophy.
} 
I consider in greater detail one of the contexts in which our ethical and epistemic aims are alleged to come into conflict (specifically, deciding whether to consider the racial composition of neighborhoods in setting home insurance premiums; Section 7). This is very much the beginning of a larger treatment of these issues. A satisfactory account of how social knowledge is accessed, and how to thwart the pernicious influence that such knowledge can have on judgment and action, requires answering a series of interrelated questions in epistemology, ethics, and psychology. My hope is to shed some light on which questions we should be asking and make tentative proposals about how to answer them.

\section{A Moral-Epistemic Dilemma?}

The point of departure for Gendler and Egan (the "dilemmists," as I will call them) is empirical research on the undesirable effects that social knowledge can have on behavior. For example, Correll et al. (2002) found that the magnitude of individuals' implicit racial bias did not correlate with their self-reported racial beliefs but did correlate with their reports of what most white Americans believe. ${ }^{3}$ In other words, it seems that merely knowing what many others believe about a group leads individuals to act in some respects as if they themselves believed it too.

Another problematic type of social knowledge might be knowledge of statistical regularities of demographic variation, such as average differences between social groups in crime rates and mathematics SAT scores (Gendler, 2011: 56). Take, for example, evidence suggesting that a woman sitting at the head of a table is often less likely to be identified as the group leader than a man in the same position (Porter and Geis, 1981). As Valian (1998: 127) explains:

failing to perceive a woman at the head of the table as the leader may have no discriminatory impetus behind it. On average, a woman is less likely to be a leader of a group than a man is ... Observers may be responding to the situation only on the basis of what is most likely, and men are more often leaders, wherever they sit. It is also important to notice, though, that regardless of the reason, a female leader sitting at the head of a table loses out compared to a male leader... She is less likely to obtain the automatic deference that marks of leadership confer upon men. Her position will be weakened-even if observers do not intend to undermine her authority.

It seems that the knowledge that women are less likely to occupy leadership positions makes people (men and women alike) less likely to treat women as

\footnotetext{
${ }^{3}$ See Arkes and Tetlock (2004) for a review. See Nosek and Hansen (2008), Jost et al. (2009), and Uhlmann et al. (2012) for responses to Arkes and Tetlock's interpretation of implicit measures as reflecting nothing but innocuous cultural knowledge.
} 
leaders. In other words, merely knowing what is statistically likely about a group leads individuals to act in some respects as if those statistical generalizations were normative, as if members of that group ought to be treated in a certain way (e.g. as if marks of leadership confer authority to men but not women). The general upshot seems to be that merely knowing certain social facts makes individuals more likely to act in biased ways. In what follows, I will, for ease of presentation, use the phrase "knowledge of stereotypes" as an umbrella term to refer jointly to all of these potentially problematic forms of social knowledge. ${ }^{4}$

The dilemmists claim that findings like these put us in an inescapable moralepistemic bind, suggesting that cases will inevitably arise in which social categories are epistemically relevant but ethically objectionable. On one side of the dilemma, we have a range of epistemic goods, e.g. knowing about prevalent stereotypes, others' beliefs, demographic facts, and so on. On the other side, we have a range of ethical goods, e.g. treating people fairly, with respect, as individuals, and so on. Pursuing the former seems to compromise the latter. As Gendler (2011: 57) writes: "Living in a society structured by race appears to make it impossible to be both rational and equitable."

Roughly, the dilemmists offer three ways in which we might respond to these findings, all of which come at a price:

We can use the categories unreflectively, and wind up with a bunch of bad stereotypeconcordant inferences, judgments, attitudes, etc. Alternatively, we can use the categories, but spend a bunch of cognitive resources suppressing or immediately excising the bad stereotype-concordant inferences, judgments, attitudes, etc. Finally, we can avoid using the categories, and fail to code up the base rate information. (Egan, 2011: 72)

In other words, the possible responses seem to be:

(STATUS QUO) To continue unreflectively using stereotypes, or perhaps even come to reflectively endorse their content;

(sUPPRESSION) To try to actively suppress the expression of our stereotypical thoughts and impulses;

(IGNORANCE) To aim to ignore or forget the stereotypes altogether. ${ }^{5}$

I assume that STATUS QUO does not strike my readers as an attractive option. It amounts to waving the white flag in the fight against prejudice. The drawbacks of

\footnotetext{
${ }^{4}$ I speak of "knowledge," rather than mere "awareness," of stereotypes, because epistemic justification is at issue. There is no moral-epistemic dilemma if the beliefs in question are false or unjustified. I ignore complications regarding whether true justified belief counts as knowledge.

5 They describe the dilemma and the three possible responses in slightly different ways at different times (Gendler, 2008: 578; 2011: 37-8, 57; Egan, 2011: 72-3). Egan notes that these responses need not be mutually exclusive.
} 
SUPPRESSION, according to the dilemmists, are that continually monitoring and suppressing our stereotypical thoughts threatens to make us so cognitively exhausted that we become less effective in reaching our other epistemic aims. It might even be self-defeating. ${ }^{6}$ By trying to become ethically better we might become epistemically worse. But what about IGNORANCE? Suppose that we could erase knowledge of stereotypes from our minds, and by doing so, eliminate all the implicitly biased behaviors that harm ourselves and others. Our automatic, intuitive responses would be perfectly aligned with our reflective commitments. Egalitarian sunshine of the spotless mind. What would be the downside?

The dilemmists suggest that this option would also be epistemically suboptimal. We would lose out on information; namely, knowledge of what others believe, of demographic regularities, and so on (Gendler, 2011: 56). By losing this information we suffer an epistemic cost. Ultimately, the dilemmists seem to think that this cost is worth bearing, and that we should embrace some combination of SUPPRESSION and IGNORANCE. ${ }^{7}$ But in what sense is IGNORANCE an epistemic cost? For that matter, what is it to be an epistemic cost? Answering this requires taking a stand on some broader issues in epistemology, which I do in Section 3. I then propose, in Section 4, that the dilemmists have either misdescribed IGNORANCE, insofar as we need not forget about stereotypes altogether in order to prevent their pernicious influence on behavior, or that they have failed to countenance a fourth option; namely, of regulating the cognitive accessibility of stereotypes, such that we can recall them when they are relevant and ignore them when not.

\section{The Aims of Knowledge}

Our epistemic aim is not to know everything. ${ }^{8}$ Perhaps this is contentious, but it does not seem true that we have an omnipresent epistemic goal to achieve

${ }^{6}$ As when trying not to think about a white bear makes you think about a white bear. See Follenfant and Ric (2010), Huebner (2009), and Madva (2012: 103-4, 158-65) for discussion of several ways that efforts to resist stereotype-consistent thoughts and behaviors can backfire.

7 Egan (2011: 78). Much of my concern here has to do with the claim that these responses are inherently epistemically costly. I doubt the dilemmists and I would disagree much over which practical strategies to pursue in order to make our behavior more aligned with our ethical aims, but rather over whether pursuing these strategies would force us to compromise our epistemic aims. I have benefited greatly from reading a longer, unpublished manuscript of Gendler (2011), in which she considers some of these ethically valuable but (putatively) epistemically costly strategies in greater depth.

${ }^{8}$ Many of my epistemological claims in what follows are indebted to Kim's $(2012,2014)$ account of goal-dependent, "all-else-neglected" rationality. Kim argues that the ideal of "all-things-considered" 
universal knowledge of all the facts there are. This is true neither of our everyday epistemic practices nor of our scientific inquiries (nor of our theories of the theory of knowledge).

Given that we are not out to know it all, the sheer loss of information is not, just as such, an epistemically bad turn of events. There are lots of facts we simply do not care about, such as whether the number of oxygen atoms in the room is even or odd. Doubtless there are many facts out there that we do not care about but should. ${ }^{9}$ I should invest more effort than I do in determining how big my carbon footprint is and what I can do to reduce it. At the same time, however, there are lots of facts we do care about but should not. I know plenty of facts that I could do just as well without. Once upon a time it seemed important to memorize all the lyrics to the opening theme song of The Fresh Prince of BelAir, but I would gladly trade in that knowledge now to free up mental space for something else. How many hours did I spend learning to write in cursive as a child, only for it to become an almost perfectly useless skill as an adult? Whether bits of knowledge like these are worth seeking or keeping is not a matter of their intrinsic value, but of their value relative to some further aim. I think that memorizing that theme song seemed important to me because I hoped it would impress my friends, but knowing the lyrics is of little use to me now (except at retro or campy dance parties).

To consider examples nearer to the topic at hand, take our basic cognitive dispositions to sort people into categories. From the beginnings of infancy, we start making distinctions between in-groups and out-groups, and forming specific expectations about how respective members of these groups will behave (Valian, 1998; Leslie, forthcoming). These cognitive dispositions are surely indispensable, enabling us to deal with the overwhelming complexity of information in the world as well as the underwhelming poverty of information that confronts us at any given moment. We could not accomplish much of anything without them; they serve some pretty fundamental aims. Nevertheless, to grant that these cognitive dispositions are indispensable on the whole is not to say that their exercise on any particular occasion is useful or accurate. While there are plenty of

rationality (of taking everything into account) is ultimately incoherent. In some respects, I am trying to apply his general theory of rationality to the particular case of knowledge of stereotypes.

9 Sometimes our ignorance reflects a motivated and systematic avoidance of information. See Mills' (1997: 18) discussion of the "epistemology of ignorance, a particular pattern of localized and global cognitive dysfunctions (which are psychologically and socially functional), producing the ironic outcome that whites will in general be unable to understand the world they themselves have made." I consider the moral culpability that individuals might bear for subtle acts of selective attention and ignorance elsewhere (Madva, 2012: ch. 3). 
useful categories and regularities that we pick up on, there are plenty of useless ones to which we devote undue attention and plenty of useful ones that we miss altogether.

Consider the relative difficulty people have in recognizing the faces of outgroup members, which Gendler (2011) discusses at length. One component of this out-group recognition deficit seems to be that participants fail to notice individuating facial features and devote undue attention to others' out-group status. This recognition deficit occurs for faces from different races as well as from different classes: middle-class white participants have a harder time recognizing faces seen in "impoverished contexts" than in "wealthy contexts" (Shriver et al., 2008). They hone in on the poverty of the social context (which is, given the task at hand, irrelevant) at the expense of noticing the idiosyncratic facial features that would enable recognition later.

Recent evidence suggests that as soon as children begin to appreciate these group differences, they also begin to invest them with spurious significance, e.g. by implicitly preferring in-groups over out-groups, and high-status social groups over low (Dunham et al., 2013). Anti-out-group biases begin to form during the first months of infancy (Ziv and Banaji, 2012) and remain surprisingly stable through adulthood. Yet while it is relatively easy to imagine how a default disposition to, say, prefer the company of the rich and powerful might be adaptive from an evolutionary perspective (e.g. because hangers-on could share in their abundant resources), such a disposition is pretty clearly bogus from a normative perspective (be it epistemic or ethical). Many in-group preferences form during childhood, but decades of research also suggest that assigning adults into patently arbitrary groups can rapidly generate in-group preferences as well (Ashburn-Nardo et al., 2001).

Perhaps the most notorious and egregious examples of investing social categories with undue epistemic significance are the so-called "fundamental" and "ultimate" attribution errors, both of which involve systematic asymmetries in the beliefs we tend to form about causes of behavior. We are more likely to seek out personalitybased explanations - and ignore situational factors - when we try to understand the bad behavior and mistakes made by others (the fundamental error; Jones and Nisbett, 1971), especially when they are out-group members (the ultimate error! Pettigrew, 1979), but exhibit the reverse tendency when it comes to explaining the mistakes made by us and our affiliates. For example, a white manager might assume that a black employee's lateness is due to laziness, while his white comanager's lateness is due to unforeseeable traffic delays caused by a car accident.

Such cases of excessive attention to certain categories, and inattention to others (which are perhaps more predictive and relevant), comprise but a few examples 
of a more general feature of our epistemic state: that we know and attend to lots of things we should not, and do not know and ignore lots of things we should. There are lots of facts that we would do just as well to forget or ignore because our preoccupation with them prevents us from seeking out and remembering information more relevant to our ends. This is not to assume that it is always straightforward to determine which information is relevant for which aims, but the difficulty of figuring out what is relevant cuts both ways. It is not as if we should just think about as much as we can, as the phrase "all things considered" suggests. Considering as much as we can because anything could be relevant is obviously going to be self-defeating. Considering patently irrelevant information, e.g. considering whether Pluto should be counted as a planet while deciding whether to turn left or right at a busy intersection, is, on its face, a bad epistemic practice, not just a gratuitous one. Sometimes it is worthwhile to err on the side of considering too much rather than too little, but doing so is nevertheless to err, to make (or increase the risk of making) a certain sort of mistake. It is to consider something that is "beside the point" or "neither here nor there," i.e. irrelevant to the truth of the proposition in question.

I grant that, at the level of scientific and communal pursuits, it might very often be preferable to err on the side of taking in too much information rather than too little. (Bring on Big Data!) Something that we take to be irrelevant now might turn out to be important down the line. Perhaps, then, we should make an extra effort to be inclusive in how many hypotheses we entertain, how much data we gather, and so on, but it obviously does not follow that we ought to take "every" hypothesis seriously, gather "all" possible data on a hypothesis, or treat everything that seems irrelevant as if it were relevant (if such norms even make sense). The history of science is replete with examples of our propensity to fixate on less predictive categories and overlook more relevant ones. We can safely say that the extensive efforts once devoted to finding a Philosopher's Stone that would turn lead into gold were wrongheaded. Such efforts were less guided by any sort of rational, inductive considerations than by fantasies of wealth and power. ${ }^{10}$ More recently, it is absurd how much empirical attention is devoted to uncovering potential evolutionary, biological, or neuroscientific explanations for the underrepresentation of women in certain fields, e.g. the current hypothesis that prenatal hormone exposure predisposes girls to be innately less interested in quantitative subjects than boys (Jordan-Young, 2010). Scientists are earnestly

\footnotetext{
10 This is, of course, not to indict alchemy in general, the history of which is intricately tied to chemistry and medicine (Principe, 2012), but only to find fault with one of its notoriously misguided pursuits.
} 
investigating the possibility that prenatal testosterone makes boys like mathematics more than girls (a possibility that is ostensibly more "PC" than the hotly debated proposal that testosterone makes boys better at mathematics). While the effects of prenatal hormone exposure on interest in mathematics is an empirical question like any other, the extensive efforts devoted to uncovering such gender differences seem misplaced, especially given the overwhelmingly credible, empirically well-supported alternative explanations in terms of social and institutional factors. It is epistemically unwarranted to devote so much attention to these hypotheses. Indeed, this is plausibly a case of attribution errors writ large, in that researchers are searching for explanations in terms of enduring features of our gendered brains instead of our situations. ${ }^{11}$

The upshot is that the loss (and the acquisition) of information is not epistemically good or bad in itself, but only so relative to some more particular aims or values. Is it an epistemic deficiency not to know the names of foreign countries and their leaders? If you want to be a public official, definitely yes. If you just want to run a chain of pizza restaurants, perhaps no. Maybe there are some things worth knowing for their own sake, without qualification, such as the Form of the Good envisioned by Plato. But stereotypes do not fall into that category.

\section{The Right Thought at the Wrong Time?}

Stereotypes might seem to be just the sorts of items we would be eager to forget. Insofar as they are often false or misleading, who needs them? Unfortunately, matters are not so simple. For one thing, it is not obvious that stereotypes are generally false (although they may still often be misleading), as in Valian's discussion of how individuals tend not to assume that a woman at the head of the table is a leader. ${ }^{12}$ We can, however, bracket questions regarding their

\footnotetext{
11 Note also that Gendler and Egan frame the moral-epistemic dilemma in terms of a single individual's cognitive limitations, not in terms of the communal advancement of scientific knowledge. The dilemma arises on the assumption that an individual can notice and track only a sharply circumscribed number and range of properties, and must therefore glom onto those properties that give her the most inductive bang for her cognitive buck. By contrast, communal pursuits of knowledge are not so sharply constrained in this way. This asymmetry between individual and communal epistemic constraints explains why scientific endeavors can afford, and even benefit from, taking in ostensibly irrelevant information, while it is typically epistemically perilous for individuals to do the same.

12 See Beeghly (2013) for further discussion. Another common error is to radically over- or underestimate the relevant probabilities (e.g. sharks are more likely to attack people than are other creatures of the sea, but radically less likely to do so than most people believe). I believe the sort of hyperaccessibility I discuss here plays a major role in distorting estimations of probability, but I will not take up that issue here.
} 
accuracy, because it is clearly important for individuals with egalitarian aims to know about stereotypes at least insofar as such knowledge enables them to recognize cases when someone suffers by virtue of being perceived in a stereotypical light. ${ }^{13}$ For example, suppose a job candidate is not hired because the employer judged, on the basis of an objectionable stereotype, that people from the job candidate's race or gender are ill-qualified for the job. We lose the ability to identify the wrong that was done if we cannot make reference to the stereotype.

Stereotypes are worth knowing, then, not for their own sake but for specific purposes. Does the importance of retaining our knowledge of stereotypes rule out an option like IGNORANCE? It does insofar as we ought not forget about stereotypes altogether, but maybe we do not really need to. We simply need to be able to think about the stereotypes for certain purposes and in certain contexts, and not in others. We go epistemically astray insofar as our knowledge of stereotypes is accessed or activated in the wrong contexts and for the wrong ends.

The dilemma with which we began, however, was ethical as well as epistemic. Knowledge of stereotypes seems to make us act out of step with our considered ethical commitments. However, a second look at the data suggests that mere possession of knowledge of stereotypes does not just as such tend to lead to implicitly biased behavior-any more than mere possession of knowledge of the falsity of stereotypes tends to lead to implicitly unbiased behavior. Typically, studies that find relationships between implicit bias and social knowledge are about highly accessible knowledge of culturally prevalent stereotypes (Arkes and Tetlock, 2004). The problem is not mere social knowledge, but rather hyperactive social knowledge, agitating our minds in moments when it ought to keep silent. The normative costs of social knowledge arise primarily insofar as that knowledge becomes too accessible. We ought to access the stereotypes when they are relevant, and ignore them when not. I take the operative "ought" here to be both epistemic and ethical. We should, if possible, embrace the response of giving up some measure of cognitive access to our social knowledge. Clearly, this does not actually amount to returning to a state of total ignorance about social stereotypes. The aim is not to unlearn what we know, and thereby surrender (potentially valuable) knowledge. We want to reduce the accessibility of knowledge of stereotypes, such that it is not the first thing that comes to mind, but not lose access to it altogether. It seems, then, that the dilemmists have mischaracterized IGNORANCE (and perhaps SUPPRESSION as well, as some of the evidence I introduce in Section 6 suggests). Alternatively, it might be more accurate to conclude that

13 There will be many cases when it is important to know about stereotypes. This case is among the least objectionable. 
the list of three possible responses offered by the dilemmists is incomplete, and I am recommending a fourth option. ${ }^{14}$ While the dilemmists refer to accessibility at several points (Gendler, 2011:37; Egan, 2011: 74), they seem not to appreciate the possibility of regulating the accessibility of our social knowledge in order to have that information available when and only when we need it.

So how might this be possible? By way of suggesting how it is, I say something, first, about how this sort of cognitive access is understood in psychology (Section 5), and second, about what we as individuals can do to change the accessibility of our knowledge-in particular, our knowledge of stereotypes and other problematic social information (Section 6).

\section{Primer on Accessibility}

A substantial body of research shows that our decisions and actions are often swayed by the bits of knowledge that are most "accessible." In some sense, some ideas come to mind more "readily" or "easily" than others. For example, I know that in the United States, individuals of Asian descent are stereotyped to excel in mathematics. I also know that this stereotype is less prevalent in Canada. ${ }^{15}$ Although I have not taken a test measuring my implicit associations between Asians and mathematical ability, I should assume that I am like most Americans (including Asian Americans) and that the American stereotypes of Asians are more accessible to me than the Canadian ones; I have been repeatedly exposed to the former and not the latter. (Nor do I predict that my biases would shift were I to cross the border from Vermont to Quebec.) Knowledge of Asianmathematics stereotypes has been so pounded into our heads as to become chronically accessible. It comes too often and too easily to mind; the mere perception of a cue related to Asians or mathematics might activate it (although we might not be fully aware that such a stereotype has been activated, or of how it influences our thoughts and behaviors).

\footnotetext{
14 Thanks to Erin Beeghly and Alice Crary, who separately urged this reformulation.

15 I learned this from a study on the accessibility of mathematics-aptitude stereotypes for women of Asian descent. Shih et al. (1999) found that Asian American female undergraduates whose "Asian identity" had surreptitiously been made salient performed better on a mathematics test than those whose "Female identity" had been made salient and those who received no priming. Researchers ran the same study with high school students in Vancouver, Canada, and found that in this case activating an Asian identity degraded mathematical performance. The mathematics-aptitude stereotype may be less prevalent in Vancouver because "the Asian community is largely recently immigrated" (82). Another possible explanation, mentioned by an anonymous referee, is the high proportion of individuals of Asian heritage in Vancouver. A recent estimate suggested that $43 \%$ of people living in Vancouver's metropolitan area are of Asian descent (Todd 2014).
} 
Over the years we learn many stereotypes that do not stick in the same way. I was once told that black people think that "white people smell like wet dogs when they come out of the rain." Hearing this certainly made an impression, but I can safely say that I have never tested it or modified my automatic dispositions (such as they are) to sniff or avert my nose around members of different races who have just come out of the rain, nor to act insecurely around non-white people after I myself have just come out of the rain. Aside from being the first example that comes to mind when I try to think of a silly stereotype, this item of knowledge is not chronically accessible.

Knowledge can also be temporarily or transiently accessible. Suppose that upon arrival in Montreal, a number of locals, including a guide at the tourism information desk, offer me this inside tip: "You know, in Montreal, the elderly are exceptionally good drivers. You should always try to hail taxis driven by very old people while you're here." I might briefly, for the next fifteen minutes or so, show some increased disposition to look favorably upon cab drivers of advanced years, but it is unlikely that my newfound knowledge (of what the Montréalais believe of the elderly) would have any enduring effect on my behavior. I might recall the information from time to time, but it would not remain close to the mental surface. Given my extensive socialization into a world where the elderly are routinely depicted as bad drivers, this newfound knowledge would exert little influence on my day-to-day dealings. Similarly, if you imagine yourself in a postapocalyptic world in which all the flowers are poisoned with radiation and the insects are the only healthy things to eat, your typical preference for roses over roaches will briefly be reversed. ${ }^{16}$ You will, on some measures, temporarily show an implicit preference for insects over flowers. But this sort of imaginative exercise will not transform you into a bug lover if you were not one already; the thoughts and feelings that come most readily to mind when you think of insects will, in a few days at the most, be much as they were before. In cases like these, a bit of knowledge is just transiently accessible, briefly rendered salient by virtue of some anecdote or exemplar.

It is fair to wonder, however, what this talk of accessibility really means. The natural ways of explaining it are metaphorical. Something is accessible, e.g. if it is hovering "in the back of your mind." Psychological definitions of accessibility are

\footnotetext{
16 See Foroni and Mayr (2005), although Han et al. (2010) found that, while these transient effects occur for the standard IAT that uses words such as "pleasant/unpleasant," they do not occur for the "personalized" IAT that uses the words "I like/I don't like." Han et al. argue that the standard IAT often measures mere "extrapersonal associations" (roughly akin to mere knowledge of prevalent stereotypes believed by others), whereas others (Nosek and Hansen, 2008) take the grammatical sentences of the personalized IAT to induce greater self-regulation.
} 
not entirely perspicuous either. Morewedge and Kahneman (2010: 435) define accessibility as "the ease with which a particular unit of information is activated or can be retrieved from memory." I have some intuitive sense of what they are talking about, but the notion of "ease of access" is rather obscure. One thing this definition brings out is that accessibility is intimately tied to the notion of knowledge activation. Eitam and Higgins (2010: 951) define accessibility and activation reciprocally:

When initially conceived, accessibility referred to the ease with which a mental representation could be activated by external stimulation, and activation meant that a representation has been accessed for use... In other words, a mental representation's accessibility referred to the amount of external stimulation needed for it to shift from a latent state (available in the mind but currently inactive) to an active one (involved in current thought and action).

Again, I more or less know what they mean, but these definitions are just cycling through synonyms: it is accessible in the sense that it is available; available in the sense that it is easily retrieved; easily retrieved in the sense that it is easily activated.

Reflecting on how accessibility is measured goes some way toward illuminating what it is. In effect, a bit of knowledge is said to be more accessible to the extent that an individual is more likely to recall it upon request, or to recall it faster. (Thus, the moral-epistemic dilemma arises in part because stereotypes are too likely and too quick to reach the mental surface.) Accessibility is then often defined computationally as "the probability of retrieval."17 "Ease" of retrieval is thereby replaced with "probability." This definition, however, still invokes "retrieval," which is effectively synonymous with "access" (as if to say, "retrieve-ability refers to the probability of retrieval"). Terms like "retrieval" do little more than relabel commonsense notions of remembering in terms of a storage-space metaphor. ${ }^{18}$ The underlying psychological constructs and

17 See Bahrick (1971). Thanks to Edouard Machery for emphasizing this.

18 Fine-grained distinctions between these terms (accessibility, availability, activation, retrieval, recall) are sometimes made, but I ignore them here. Another concern is that it is completely nonobvious why probability and speed of recall should be lumped together as two measures of a single construct, accessibility. An anonymous referee suggested that this problem could be addressed by defining accessibility in terms of the cues that bring a piece of information to mind. The referee rightly emphasizes the importance of cues, e.g. one person might only (be likely to) remember $p$ given a specific prompt, whereas another might (be likely to) remember $p$ across a broad range of cues. Perhaps, then, we should understand accessibility as a triadic relation between a person, a proposition, and a cue (or set of cues). However, this point does not help to solve the problems noted here, e.g. why to lump together probability and speed of recall. For each triad, we can ask how likely a subject $S$ is to encounter cue $c$, how likely $S$ is to remember $p$ given $c$, how quickly $S$ will remember $p$ given $c$, and so on. All of these come apart. $S$ might be extremely reliable at remembering $p$ across a 
operations remain murky. For now, perhaps the best way to understand accessibility is to understand how to change it.

\section{The Malleability of Accessibility: Concrete Strategies}

Reducing the accessibility of our knowledge only constitutes a normative cost, whether epistemic or ethical, if we cannot access that knowledge when we need it. If we can intervene to influence the accessibility of our knowledge in the right way, we can mutually satisfy (or at least come significantly closer to mutually satisfying) our epistemic as well as ethical aims. Can we do this?

It is not just wishful thinking to envision lining up the relative accessibility of our knowledge with our ethical aims. There is a significant tradition of research suggesting that accessibility is often highly goal-dependent. ${ }^{19}$ What most readily comes to mind is often a function of what is most relevant to our aims. Some of the most important aims in this regard are those of being fair and egalitarian, as I explain later in this section. But there are surprising ways in which other aims can help us reduce the accessibility of stereotypes as well.

For example, one way to block the activation of stereotypical thoughts seems to be to adopt the aim of being creative. Stereotypical thinking is typical thinking; it is unoriginal. Agents who are motivated to think creatively will automatically ignore stereotypical associations. In Sassenberg and Moskowitz (2005), some participants were put in a "creative mindset" by being asked to recall a few occasions in which they had been creative. Participants next performed a lexical decision task, which required them to identify as fast as possible whether letters on a computer screen made up a real word or not. They saw either a black or

broad range of cues, but comparatively slow to do so, e.g. $S$ is a champion at leisurely solving crossword puzzles but a miserable failure at time-sensitive memory tasks, such as the quiz show Jeopardy!. There are many facts which I have no chance of recalling except when given a highly specific cue, but which, given that cue, I may recall extremely quickly, e.g. I may (instantly) remember the thirtieth word of a song lyric only when I hear the recording of the song leading up to it. For many songs, the probability that I will remember the next line may be extremely low, but if I do remember it at all, I will remember it quickly. And so on.

19 See Kunda and Spencer's (2003) goal-dependent theory of stereotype activation, which they define as "the extent to which a stereotype is accessible in one's mind" (522). For reviews, see Moskowitz (2010) and Uhlmann et al. (2010). Eitam and Higgins (2010) seek to explain accessibility entirely in terms of the "motivational relevance" of a bit of knowledge to an agent, and even recommend replacing the term "accessibility" with "relevance" (e.g. distinguishing "chronic" from "transient" relevance: 960). Given its obscurity, abandoning the term "accessibility" might be wise, but is "relevance" an obvious improvement? That equally fraught term/concept threatens to muddle description with prescription, i.e. the distinction between what agents happen to take to be relevant and what actually (as a normative matter) is relevant. I use the term "relevance" here exclusively in the normative sense. 
white male face immediately followed by a nonsense word, a stereotypeconsistent word, or a stereotype-irrelevant word. For example, an image of a black face followed by the word "rhythmic" would be a stereotype-consistent pairing. Those who had been primed to be creative were significantly slower to identify stereotype-consistent words than stereotype-irrelevant words, whereas participants in other conditions exhibited the reverse tendency. The stereotypical associations were irrelevant to the task of distinguishing words from non-words, and the goal of being creative enabled participants to ignore that irrelevant but otherwise chronically accessible knowledge. Being in a creative mindset prevented the stereotypes from being the first thoughts to come to mind. ${ }^{20}$ Research on inducing a creative mindset is especially striking because there is no evidence that the manipulation saps cognitive resources or leads to the problematic "rebound" effects associated with the conscious or unconscious monitoring of unwanted thoughts (Sassenberg et al., 2004). As Sassenberg and Moskowitz (2005: 507) explain, "being primed with creativity allows for generating original ideas because one is able to think differently without the unwanted side effects of suppressing thoughts triggered by the intention to suppress them." The evidence suggests that a creative mindset really does reduce the accessibility of stereotypes, rather than simply motivating participants to refrain from applying stereotypes after they come to mind.

In that case, the goal to be creative was more or less unwittingly activated. Are there conscious, intentional strategies for influencing accessibility? This may be exactly the effect of implementation intentions, which are if-then plans that link a specific cue to a specific response, such as: "If I feel a craving for cigarettes, then I will chew gum!" Concrete plans specifying when, where, and how an action will be performed are far more effective than unspecific plans, such as: "I should cut down on smoking!" Webb and Sheeran (2008) argue that these if-then plans work in part by making the specified cue more accessible. Participants who formed an if-then plan to retrieve a coupon after the experiment exhibited heightened access to the "if" components of the plan on a lexical decision task like the one just described. They were also almost twice as likely to follow through

20 This study may point to certain aesthetic implications of research on implicit cognition. Recommending that we should resist relying on stereotypes in art might ring in some ears as advocating the oppression of artistic creativity. But studies like this suggest that stereotypes are precisely not creative. Of course, creativity is a complex phenomenon. For example, an artist-or a comedian (Anderson, 2012b) - can appeal to a stereotype in order to subvert it. My point is simply that research on social cognition does not bespeak any fundamental opposition between our aesthetic and ethical aims (any more than it does between our epistemic and ethical aims). Reducing the accessibility of stereotypes might even improve creativity by preventing us from falling back on hackneyed depictions of members of social groups. 
on retrieving the coupon than were participants who did not form an if-then plan. In contexts where we know we are wont to attend to the wrong categories, we can form if-then plans to guide our attention to the right ones.

The influence of implementation intentions on "shooter bias" is a case in point. Participants must press a button labeled "shoot" when they see an image of a person holding a gun, and "don't shoot" when they see a person holding a cell phone. Many participants, including African Americans, are faster and more likely to "shoot" unarmed blacks than unarmed whites. Mendoza et al. (2010) found that participants' shooter bias was significantly reduced after they formed intentions, such as: "If I see a gun, then I will shoot!" This intention plausibly makes the relevant cue (the gun) more accessible, and makes the irrelevant cues (such as the race of the person holding it) less accessible. In fact, there is no more relevant cue than the gun in this context. Participants are directing their attention to the precise property required by the task, so, given the dilemmists' assumption that our cognitive finitude requires us to focus on just a few features, this strategy incurs pure epistemic benefit with no cost. Stewart and Payne (2008) found that participants who formed the intention to think the word "safe" when they saw a black face also showed significantly less implicit racial bias. Thinking counterstereotypical thoughts seems to reduce the accessibility of stereotypical ones.

Insofar as we already know the content of many stereotypes, and we are learning more and more about the contexts in which stereotypes do harm, then we can formulate if-then plans that pick out those contexts and specify responses. In the case of shooter bias, researchers identified a context in which racial stereotypes are highly accessible, and specified responses that counteract the stereotype. Generally speaking, in cases where stereotypes are apt to do harm, the right if-then plans might have a structure roughly along the lines of: "If I perceive a member of group $\mathrm{G}$ in context $\mathrm{C}$ (acting in way $\mathrm{W}$, or being treated in way $\mathrm{Y}$ ), then I will perform action A!” During Q\&A after a lecture in December 2011, Louise Antony proposed that a person concerned to avoid overinterrupting women could form the plan: "If she's talking, then I won't!"

Many of these plans will be other-directed, in that they regard how we treat others, but we can also form self-directed plans to arm ourselves against potentially harmful environmental cues and stereotype threat. For example, a person stereotyped to underperform in mathematics can block the negative effects of stereotype threat by forming the plan: "And if I start a new problem, then I will tell myself: I can solve it!” Bayer and Gollwitzer (2007) found that participants who rehearsed this plan solved significantly more problems on a test of logical reasoning than those who rehearsed other plans, such as: "And I will tell myself: I can solve these problems!" 
I mentioned that the accessibility of knowledge is highly goal-dependent, but I have not discussed the goals most relevant to reducing the accessibility of stereotypes: namely, the aims to be fair and unbiased. There is substantial evidence that these aims are effective as well, whether they are held chronically or transiently (Moskowitz, 2010). The goal to be unprejudiced can be induced, for example, by having participants contemplate a time when they failed to live up to this ideal. Some agents seem to have chronic egalitarian goals that are automatically activated when they find themselves in a situation in which they or others might be inclined to act in a biased way. Perhaps they have internalized the plan, "If I see injustice, then I will fight it!"

Figuring out precisely which if-then plans to adopt is a substantive project, but I see no reason to be pessimistic about taking that project pretty far. For example, perhaps one appropriate plan might be: "If I see a woman at the head of the table, then I will treat her like a leader!" Then again, perhaps the plan ought to refer generically to a person at the head of the table, which could help reduce the influence of other sorts of biases, e.g. regarding race, class, and disability. ${ }^{21}$ However, if men are generally more likely to be seated at the heads of tables, then referring generically to a person might simply reinforce our initial disposition to assume men are leaders. I am skeptical that the "person" formulation would incur such unforeseen, undesirable consequences, but it is an open empirical matter. My broader point is that, like all heuristics and rules of thumb, no simple if-then plan (or collection of such plans) will provide a universally accurate guide to true belief or right action. Implementation intentions are not a magical cure-all for discrimination. Nor will they empower us to transcend human finitude and fallibility. Whichever plans we identify as most effective for advancing our aims, there will always be tradeoffs, with certain plans working better in certain contexts and for certain purposes but not others.

As far as I can tell, however, these tradeoffs need not be between our ethical and epistemic aims. The initial dilemma was that knowledge of stereotypes led to unethical behavior, and that ethical improvement would incur epistemic costs. Supposing that implementation intentions lead to ethical improvement, do they bring the costs of SUPPRESSION and IGNORANCE in tow?

Employing these if-then plans constitutes a kind of self-control, but they do not sap our limited cognitive resources. Implementing them is not a matter of engaging in SUPPRESSION-or, to the extent that they do involve SUPPRESSION, then that option need not be as epistemically costly as the dilemmists suggest. Rehearsing them is easy and, once formed, putting them into action often

21 Thanks to Jenny Saul for helping me think through this example. 
requires little or no additional effort. Gollwitzer and Sheeran (2006) go so far as to call them "instant habits." Of course, there will be limitations to how radically an if-then plan can reconfigure our ingrained dispositions, but there is no question that these plans provide a powerful way to influence the accessibility of our knowledge. Another way to reduce the accessibility of stereotypes is to practice, e.g. repeatedly affirming counterstereotypes. For example, repeatedly pressing a button labeled "YES" in response to counterstereotypical stimuli, such as a black face paired with the word "friendly," significantly reduces stereotype accessibility (Kawakami et al., 2000).

Moreover, these interventions do not cause participants to completely forget about stereotypes. It is implausible that a person with the right retraining, mindset, or if-then plan would somehow cease to know the contents of prevalent stereotypes. She would not suddenly profess ignorance about stereotypes regarding, say, Asians and mathematical aptitude. She might, however, have a harder time coming up with a list of such stereotypes out of the blue. ${ }^{22}$ This is, I suggest, essentially what we are pursuing in trying to line up the accessibility of our knowledge with our ethical aim of treating others fairly.

I by no means intend to suggest that implementing these and other strategies will swiftly transport us to an ideal state of moral-epistemic virtue where we can access our knowledge at all and only the right times and where all our impulses and habits will be effortlessly unprejudiced. Rehearsing these if-then plans and training procedures are, I submit, the anti-prejudicial equivalent of using flashcards to memorize a new vocabulary. The expectation is not that adopting these cue-behavior rules of thumb will transform us into ethically and epistemically ideal agents, any more than memorizing a set of rules and words will transform an individual into a fluent speaker of a second language. ${ }^{23}$ Nevertheless, these ifthen plans enable us to make meaningful progress in that direction, towards lining up our accessible social knowledge with our considered aim of being egalitarian-without incurring epistemic costs. We can significantly close the distance between our current sorry state and our normative ideals, and, in closing this distance, we need not make a forced choice between pursuing ethical and epistemic aims.

${ }^{22}$ I doubt this has been tested, but I predict that such debiased participants would be able to check off a list of stereotypes put in front of them, but be less able to generate an extensive list of such stereotypes without prompting. Some evidence suggests, however, that open-ended list-generating is an unreliable indicator of stereotype knowledge and accessibility (Nosek and Hansen, 2008).

${ }^{23}$ For more on the analogy between egalitarian agency and linguistic fluency, see my (2012: ch. 4). 


\section{Tragic Cases?}

In Section 6 I emphasized cases, such as the influence of a creativity mindset, where stereotypes are irrelevant. What happens when stereotypes are relevant to the task at hand? Not to trivialize the issue, but that is when we should access them. The dilemmists, however, seem to have cases in mind where stereotypes are, specifically, epistemically relevant but ethically objectionable.

A prominent case that Gendler and Egan discuss is Tetlock et al.'s (2000) study on "forbidden base rates." Participants were asked to imagine an executive setting the premiums on home insurance in various neighborhoods. All participants were told that some of the neighborhoods were higher risk than the others. Some participants were also told that the high-risk neighborhoods were predominantly black, while others received no information about race. Here is the entire scenario participants read in the race-relevant condition:

Dave Johnson is an insurance executive who must make a decision about whether his company will start writing home insurance policies in six different towns in his state. He classifies three of the towns as high risk: $10 \%$ of the houses suffer damage from fire or break-ins each year. It turns out that $85 \%$ of the population of these towns is Black. He classifies the other three towns as relatively low risk: less than $1 \%$ of the houses suffer fire or break-in damage each year. It turns out that $85 \%$ of the population of these towns is White. (Tetlock et al., 2000: 860-1)

Participants who were not given any race-related information tended to say that the executive should charge a higher insurance premium for the houses in the high-risk neighborhoods, but those given the information about race insisted that he should charge the same premium for all (this was especially true for politically liberal participants). Gendler (2011: 55) refers to this as "a kind of epistemic self-censorship on non-epistemic grounds.” Tetlock et al. (2000: 853) suggest that these "people are striving to achieve neither epistemic nor utilitarian goals," and specifically compare this case to the classic base-rate neglect literature (854).

However, it is not clear why we should think of this as a dilemma between epistemic and non-epistemic (moral) requirements. In fact, we do not know which requirements are at issue, because we do not know which problem the participants took themselves to be solving. We do not know what their aims were. The participants were not, for example, told in advance that they should make the decision in the best economic interests of the insurance executive. All they were told was that "the research goal was to explore how people make judgments" (860). Plausibly, the participants who just read about high-risk neighborhoods and insurance premiums, without any reference to race, 
thought the task was just how to maximize profits, or something similar. But once race was introduced, they may very well have thought the task was how best to avoid being prejudiced, or even how to compensate for systemic racial injustice! This is quite plausible in light of how overt the reference to race was. Even Tetlock et al. explain that

liberals did not indiscriminately embrace any justification for not using the base rates. Liberals viewed the pragmatic or empirical grounds offered for dismissing the base rates as implausible. They were not more inclined to challenge the statistics or to argue that the best long-term profit-maximizing strategy is to charge the same price. Instead, liberals invoked a straightforward moral defense against policies that harmed the already disadvantaged. (863-4)

Relative to the aim of preventing racial injustice, there is nothing epistemically deficient about discounting the background information about high-risk neighborhoods. Participants may have been explicitly counting that information as part of the justification for charging the same premiums, because this policy would prevent the exacerbation of injustice. To be clear, I am not proposing that some participants adopted the "epistemic" aim of maximizing profits while others adopted the "ethical" aim of redressing injustice. Both groups had "epistemic" aims in the sense that they were trying to form true justified beliefs (about, respectively, how to make money and how to avoid placing additional burdens on those already disadvantaged). The real test would be if participants who had categorically adopted the goal of maximizing profits still overlooked this information when race was introduced.

If I am right about the Tetlock study, then its failure to constitute a genuine moral-epistemic dilemma is telling. Such cases might be harder to find than one might think. What seemed like a moral-epistemic dilemma might be no dilemma at all, because a morally tinged aim sets the epistemic agenda. There is nothing inherently wrong with the epistemic agenda being set by a moral aim; there has got to be some aim or other, and it might as well be a moral one. Consider, for example, the long tradition of research seeking to identify factors that predict death-sentencing. Recently, Eberhardt and colleagues (2006) found that deathsentencing "is influenced by the degree to which a Black defendant is perceived to have a stereotypically Black appearance" (383), and Williams and Holcomb (2004) found that a death sentence is significantly more likely in cases when the victim is white and female. Of course, knowledge of these predictive factors is not being pursued "for its own sake," but because we want to know whether the practice of capital punishment is fair. If the race and gender of defendants and victims are strong predictive factors, that gives us reason to believe that the practice is not fair. The purely epistemic project of acquiring true beliefs 
about the factors that predict death sentences is, in other words, set in motion by ethical aims. ${ }^{24}$

I believe that there can be tragic normative conflicts with no ideal solution, such as Sartre's classic example of the individual torn between fighting in the revolution and staying home to take care of his ailing mother, and I will not offer a principled argument against the possibility of similar unresolvable conflicts arising between ethics and epistemology. I submit, however, that we have not been given definitive examples of these which pit the ethical fight against prejudice against the epistemic project of identifying the properties that give us the most inductive bang for our buck. Insofar as genuine conflicts between epistemic and ethical aims do arise in lived experience, solving them may often not be a matter of choosing which to pursue and which to sacrifice, but reconsidering the merits of the aims themselves. I have assumed that we are holding our aims fixed, but they themselves can be called into question. If our ethical and epistemic aims conflict, that may signal that we are operating with the wrong aims. Participants who ignored the information about high-risk neighborhoods may not have been compromising their epistemic aims; they may have been (rationally) revising them.

I hope these considerations suggest that the dilemma is less of a theoretical nature, about the principled impossibility of jointly satisfying competing normative requirements, and more of a practical nature, about what we can do concretely to thwart the pernicious influence that knowledge of stereotypes has on our judgment and behavior. There is reason to be optimistic that we can improve along this ethical front, and that we can do so without compromising our epistemic aims, if only we try.

\section{Acknowledgements}

Thanks to Erin Beeghly, Michael Brownstein, Katie Gasdaglis, and Christia Mercer for extensive feedback on drafts, and to Jenny Saul both for insightful and encouraging comments on various drafts and for organizing the wonderful Implicit Bias and Philosophy Workshops at the University of Sheffield, where I first presented many of these ideas in April 2012. I benefited greatly from the questions at my talk, especially from Miranda Fricker, Edouard Machery, and Ron Mallon, and learned much from the other brilliant psychologists and philosophers I met. I am also grateful for feedback at the Wittgenstein Workshop at the New School for Social Research in September 2012, especially from Alice Crary and Janna Van Grunsven; at the Townsend Fellows seminar at UC-Berkeley, where I learned much from Michael Nylan's comments; and during my Spring 2013 seminar at Berkeley, especially from Shannon Doberneck, Jeremy Pober, and Jen White.

24 See Anderson (2004) for more on the role of "value judgments" in science. 


\section{ALEX MADVA}

\section{References}

Anderson, E. (2004). "Uses of value judgments in science: A general argument, with lessons from a case study of feminist research on divorce." Hypatia 19(1): 1-24.

Anderson, E. (2010). The Imperative of Integration. Princeton, NJ: Princeton University Press. Anderson, E. (2012a). "Epistemic justice as a virtue of social institutions." Social Epistemology 26(2): 163-73.

Anderson, L. (2012b). "Why so serious? An inquiry into racist jokes." Presentation for the Implicit Bias and Philosophy Workshop, University of Sheffield, April 2012.

Antony, L. (2002). "Quine as feminist: The radical import of naturalized epistemology." In Antony, L. M., Witt, C., and Atherton, M. (eds.)., A Mind of One's Own, Feminist Essays on Reason and Objectivity, 2nd edn. Boulder, CO: Westview Press: 110-53.

Arkes, H. R. and Tetlock, P. E. (2004). "Attributions of implicit prejudice, or 'would Jesse Jackson 'fail' the Implicit Association Test?'” Psychological Inquiry 15: 257-78.

Ashburn-Nardo, L., Voils, C.I., and Monteith, M. J. (2001). "Implicit associations as seeds of intergroup bias: How easily do they take root?" Journal of Personality and Social Psychology 81: 789-9.

Bahrick, H. P. (1971). "Accessibility and availability of retrieval cues in the retention of a categorized list.” Journal of Experimental Psychology 89(1): 117-25.

Bayer, C. and Gollwitzer, P. M. (2007). "Boosting scholastic test scores by willpower: The role of implementation intentions." Self and Identity 6: 1-19.

Beeghly, E. (2013). Seeing Difference: The Epistemology and Ethics of Stereotyping. $\mathrm{PhD}$ dissertation, University of California, Berkeley.

Brownstein, M. S. and Madva, A. M. (2012a). "Ethical automaticity." Philosophy of the Social Sciences 42(1): 68-98.

Brownstein, M. S. and Madva, A. M. (2012b). “The normativity of automaticity.” Mind and Language 27(4): 410-34.

Correll, J., Park, B., Judd, C. M., and Wittenbrink, B. (2002). "The police officer's dilemma: Using ethnicity to disambiguate potentially threatening individuals." Journal of Personality and Social Psychology 83(6): 1314-29.

Dunham, Y., Chen, E., and Banaji, M. R. (2013). "Two signatures of implicit intergroup attitudes: Developmental invariance and early enculturation." Psychological Science 24: $860-8$.

Eberhardt, J. L., Davies, P. G., Purdie-Vaughns, V. J., and Johnson, S. L. (2006). “Looking deathworthy: Perceived stereotypicality of black defendants predicts capital-sentencing outcomes." Psychological Science 17(5): 383-6.

Egan, A. (2011). 'Comments on Gendler's 'The epistemic costs of implicit bias.' Philosophical Studies 156: 65-79.

Eitam, B. and Higgins, E. T. (2010). "Motivation in mental accessibility: Relevance of a representation (ROAR) as a new framework." Social and Personality Psychology Compass 4(10): 951-67.

Follenfant, A., and Ric, F. (2010). "Behavioral rebound following stereotype suppression. European Journal of Social Psychology 40(5): 774-82.

Foroni, F. and Mayr, U. (2005). "The power of a story: New, automatic associations from a single reading of a short scenario.” Psychonomic Bulletin and Review 12(1): 139-44. 
Gendler, T. S. (2008). “Alief in action (and reaction)." Mind and Language 23(5): 552-85. Gendler, T. S. (2011). "On the epistemic costs of implicit bias." Philosophical Studies 156: 33-63. Gollwitzer, P. M. and Sheeran, P. (2006). "Implementation intentions and goal achievement: A meta-analysis of effects and processes." In Zanna, M. P. (ed.), Advances in Experimental Social Psychology. New York, NY: Academic Press: 69-119.

Huebner, B. (2009). "Trouble with stereotypes for Spinozan minds." Philosophy of the Social Sciences 39: 63-92.

Jones, E. E. and Nisbett, R. E. (1971). "The actor and the observer: Divergent perceptions of the causes of behavior." In Jones, E. E., Kanouse, D. E., Kelley, H. H., Nisbett, R. E., Valins, S., and Weiner, B. (eds.), Attribution: Perceiving the Causes of Behavior. Morristown, NJ: General Learning Press: 79-94.

Jordan-Young, R. (2010). Brain Storm: The Flaws in the Science of Sex Differences. Cambridge, MA: Harvard University Press.

Jost, J. T., Rudman, L. A., Blair, I. V., Carney, D. R., Dasgupta, N., Glaser, J., and Hardin, C. D. (2009). "The existence of implicit bias is beyond reasonable doubt: A refutation of ideological and methodological objections and executive summary of ten studies that no manager should ignore." Research in Organizational Behavior 29: 39-69.

Han, H. A., Czellar, S., Olson, M. A., and Fazio, R. H. (2010). Malleability of attitudes or malleability of the IAT? Journal of Experimental Social Psychology 46: 286-98.

Kalev, A., Dobbin, F., and Kelly, E. (2006). "Best practices or best guesses? Assessing the efficacy of corporate affirmative action and diversity policies." American Sociological Review 71(4): 589-617.

Kawakami, K., Dovidio, J. F., Moll, J., Hermsen, S., and Russin, A. (2000). "Just say no (to stereotyping): Effects of training in the negation of stereotypic associations on stereotype activation." Journal of Personality and Social Psychology 78: 871-88.

Kim, B. (2012). The Context-Sensitivity of Rationality and Knowledge. PhD dissertation, Columbia University, New York.

Kim, B. (2014). "The locality and globality of instrumental rationality: The normative significance of preference reversals." Synthese. Advance online publication, doi 10.1007/s11229-014-0529-8.

Kunda, Z. and Spencer, S. J. (2003). "When do stereotypes come to mind and when do they color judgment? A goal-based theoretical framework for stereotype activation and application." Psychological Bulletin 129(4): 522-44.

Leslie, S. J. (forthcoming). “The original sin of cognition: Fear, prejudice, and generalization." The Journal of Philosophy.

Levinson, J. D., and Smith, R. J. (eds.) (2012). Implicit Racial Bias Across the Law. Cambridge: Cambridge University Press.

Madva, A. M. (2012). The Hidden Mechanisms of Prejudice: Implicit Bias and Interpersonal Fluency. PhD dissertation, Columbia University, NY.

Mendoza, S. A., Gollwitzer, P. M. and Amodio, D. M. (2010). "Reducing the expression of implicit stereotypes: Reflexive control through implementation intentions.” Personality and Social Psychology Bulletin 36(4): 512-23.

Mills, C. W. (1997). The Racial Contract. Ithaca, NY: Cornell University Press.

Morewedge, C. K. and Kahneman, D. (2010). "Associative processes in intuitive judgment." Trends in Cognitive Sciences 14(10): 435-40. 


\section{ALEX MADVA}

Moskowitz, G. B. (2010). "On the control over stereotype activation and stereotype inhibition." Social and Personality Psychology Compass 4(2): 140-58.

Nosek, B. A. and Hansen, J. J. (2008). "The associations in our heads belong to us: Searching for attitudes and knowledge in implicit evaluation." Cognition and Emotion 22(4): 553-94.

Pettigrew, T. F. (1979). “The ultimate attribution error: Extending Allport's cognitive analysis of prejudice." Personality and Social Psychology Bulletin 5(4): 461-76.

Porter, N. and Geis, F. L. (1981). "Women and nonverbal leadership cues: When seeing is not believing." In Mayo C. and Henley, N. (eds.) Gender, Androgyny, and Nonverbal Behavior. New York: Springer: 39-61.

Principe, L. M. (2012). The Secrets of Alchemy. Chicago, IL: University of Chicago Press.

Sassenberg, K., Kessler, T., and Mummendey, A. (2004). "When creative means different: Activating creativity as a strategy to initiate the generation of original ideas." Unpublished manuscript, Friedrich-Schiller University, Jena, Germany.

Sassenberg, K. and Moskowitz, G. B. (2005). "Don't stereotype, think different! Overcoming automatic stereotype activation by mindset priming." Journal of Experimental Social Psychology 41: 506-14.

Shih, M., Pittinsky, T. L., and Ambady, N. (1999). "Stereotype susceptibility: Identity salience and shifts in quantitative performance." Psychological Science 10: 80-3.

Shriver, E. R., Young, S. G., Hugenberg, K., Bernstein, M. J., and Lanter, J. R. (2008). "Class, race, and the face: Social context modulates the cross-race effect in face recognition." Personality and Social Psychology Bulletin 34(2): 260-74.

Stewart, B. D. and Payne, B. K. (2008). "Bringing automatic stereotyping under control: Implementation intentions as efficient means of thought control." Personality and Social Psychology Bulletin 34: 1332-45.

Tetlock, P. F., Kristel, O., Elson, B., Green, M., and Lerner, J. (2000). “The psychology of the unthinkable: Taboo trade-offs, forbidden base rates, and heretical counterfactuals." Journal of Personality and Social Psychology 78(5): 853-70.

Todd, D. (2014). "Vancouver is the most 'Asian' city outside Asia. What are the ramifications?" Staff Blog, The Vancouver Sun, March 28.

Uhlmann, E. L., Brescoll, V. L., and Machery, E. (2010). "The motives underlying stereotype-based discrimination against members of stigmatized groups." Social Justice Research 23(1): 1-16.

Uhlmann, E. L., Poehlman, T. A., and Nosek, B. A. (2012). “Automatic associations: Personal attitudes or cultural knowledge?” In Hanson, J. D. (ed.), Ideology, Psychology, and Law. New York, NY: Oxford University Press: 228-60.

Valian, V. (1998). Why so Slow? The Advancement of Women. Cambridge, MA: MIT Press.

Valian, V. (2010). "What works and what doesn't: How to increase the representation of women in academia and business." In Gender Change in Academia. Wiesbaden: VS Verlag für Sozialwissenschaften: 317-28.

Webb, T. L. and Sheeran, P. (2008). "Mechanisms of implementation intention effects: The role of goal intentions, self-efficacy, and accessibility of plan components." British Journal of Social Psychology 47: 373-95. 
Williams, M. R. and Holcomb, J. E. (2004). "The interactive effects of victim race and gender on death sentence disparity findings." Homicide Studies 8(4): 350-76.

Ziv, T. and Banaji, M. R. (2012). "Representations of social groups in the early years of life." In Fiske, S. T. and Macrae, C. N., The SAGE Handbook of Social Cognition, London: Sage: 372 . 